\title{
STUDIES ON THE CIRCULATORY CHANGES IN THE DOG PRODUCED BY ENDOTOXIN FROM GRAM-NEGATIVE MICROORGANISMS
}

\author{
By MAX H. WEIL, LLOYD D. MACLEAN, MAURICE B. VISSCHER, AND \\ WESLEY W. SPINK
}

(From the Departments of Medicine, Physiology and Surgery, University of Minnesota Medical School, Minneapolis, Minn.)

(Submitted for publication March 29, 1956; accepted June 29, 1956)

A clinical problem of increasing magnitude is the occurrence of hypotension in patients with bacteremia associated with the liberation of endotoxin from gram-negative microorganisms (1-3). Although the local vascular effects of endotoxin have been extensively studied in animals, particularly with reference to necrotizing effects on tumors $(4,5)$ and the Schwartzman reaction (6, $7)$, the hemodynamic alterations produced by these bacterial products remain unexplained. Endotoxins constitute a group of similar chemical substances identified as protein-polysaccharide complexes (8). In the course of a series of investigations reported elsewhere $(9,10)$, it was found that the pattern of the shock and the pathological changes in the gastrointestinal tract produced by the intravenous injection of endotoxins derived from Brucella melitensis, Escherichia coli, Serratia marcescens ${ }^{1}$ and Salmonella typhosa ${ }^{1}$ were indistinguishable. The uniform pathophysiological changes permit the tentative assumption that various endotoxins are closely related with respect to their pharmacological activity (11).

Intravenous administration of endotoxin in suitable doses to anesthetized adult dogs regularly produces a precipitous fall in arterial blood pressure and a simultaneous rise in portal vein pressure. Very similar changes, except for quantitative differences, have been observed in the cat, the rabbit, and the rat. These changes have been traced to pooling of blood in the portal system and particularly in the liver (12). In the dog, the portal vein pressure returns to baseline levels and partial recovery of the arterial pressure occurs during the first 15 minutes after injection. Over

1 Endotoxin from Serratia marcescens was kindly supplied by Dr. M. J. Shear, National Cancer Institute, and endotoxin from Salmonella typhosa by Dr. Dennis Watson of the University of Minnesota. the following 1 to 5 hours the arterial pressure again falls to lower values from which it does not ordinarily recover (10).

Since the sequence of hemodynamic events following injection of endotoxin to adult dogs was constant and reproducible, this method seemed well suited for further inquiry into the mechanism of the type of shock that is produced by these bacterial products. The present studies represent an attempt to define the initial cardiovascular alterations which are responsible for the profound blood pressure changes previously observed.

\section{MATERIALS AND METHODS}

Endotoxin. Purified endotoxin of the Boivin type derived from $E$. coli or $B r$. melitensis was used for most of the experiments. The method of preparing this type of endotoxin has been previously described (13). Washed, heat-killed E. coli organisms grown on "Albimi" Brucella agar medium and diluted in an equal volume of sterile saline were employed in many experiments. Earlier observations had established that this "crude" endotoxin and the highly purified endotoxins produce identical hemodynamic changes (10). In several later experiments "crude" endotoxin containing $50 \mathrm{mg}$. of dried bacterial bodies per cu. ml. was prepared from cells grown in synthetic (non-protein containing) media according to a technique described by Braude, Carey, Sutherland, and Zalesky (14). Purified Br. melitensis and $E$. coli endotoxin were used in a dosage of 10 and $5 \mathrm{mg}$. per $\mathrm{kg}$. respectively, and "crude" endotoxins were used in a dosage of $0.3 \mathrm{ml}$. per $\mathrm{kg}$. Shock was produced by a single injection given intravenously.

Procedures. Adult mongrel dogs were used and all experiments were conducted under pentobarbital sodium anesthesia except for studies of cardiac output which were done under thiopental sodium. In each case, the anesthetic was given intravenously in a dosage of $30 \mathrm{mg}$. per $\mathrm{kg}$. with supplementary doses as needed. Arterial pressures were measured in the femoral or carotid artery. Portal vein pressure was measured by a catheter advanced into the vessel from a splenic branch vein. Pressures were recorded by means of Statham strain 
gauge manometers with optimal damping and a Sanborn Polyviso recorder. Calibrations were made with a mercury manometer. Endotoxin was injected into the femoral vein or into venous tubing leading to the right atrium.

Inferior vena cava pressures either above or below the diaphragm were measured in six animals through catheters advanced from the femoral vein. Subcutaneous small vein pressure was measured in a dorsal foot vein in three dogs according to a technique described by Haddy, Richards, Alden, and Visscher (15).

Cardiac output was determined in four dogs before and at specified intervals after the injection of endotoxin using the dye-dilution technique of Nicholson and Wood (16). Evans blue dye (T-1824) was introduced into the right atrium through a catheter advanced from the jugular vein. Continuous photokymographic recordings of dye concentration in blood from the carotid artery were made using the cuvette oximeter.

Total body perfusion was performed with an oxygendispersion type of pump-oxygenator as described by Clark, Gollan, and Gupta (17). The system was primed with an excess of blood obtained by exsanguination of two large donor dogs. Oxygenated blood was introduced into the left subclavian artery and venous blood was picked up from the right auricle. The heart was entirely excluded from the circulation by the ligation of the pulmonary artery and the aortic root. Constant pressure perfusion was maintained in one experiment by use of a Sigmamotor pump and a Starling resistor as a shunt. The pump, maintained at constant output, was used for total perfusion experiments in two dogs.

Vascular pooling was measured in six dogs using a reservoir system which was interposed between the cen-

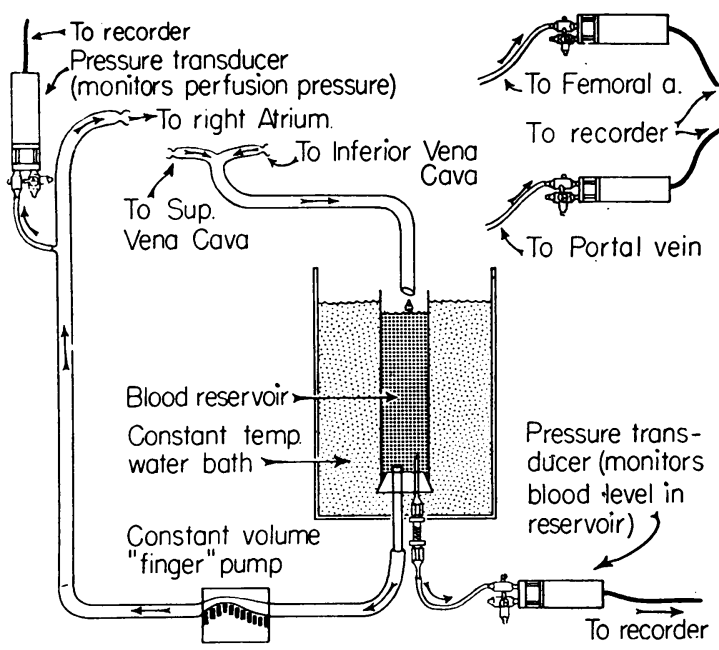

Fig. 1. Arrangement of the Reservoir System and the Recording Instruments for the Quantitation of VenOUS RETURN

tral ends of the great veins and the heart (Figure 1). The reservoir consisted of a glass cylinder maintained in a $37^{\circ} \mathrm{C}$ water bath which was placed $30 \mathrm{~cm}$. below the heart level of the experimental animal. Unoxygenated blood was pumped from the base of the cylinder to the right atrium employing a Sigmamotor pump. The volume of blood in the cylinder was measured by the hydrostatic pressure of the fluid column acting on a strain gauge manometer. The atrial infusion pressure was used as a monitor. Since this pressure was created by flow through a tube to the right atrium, the pressure varied as

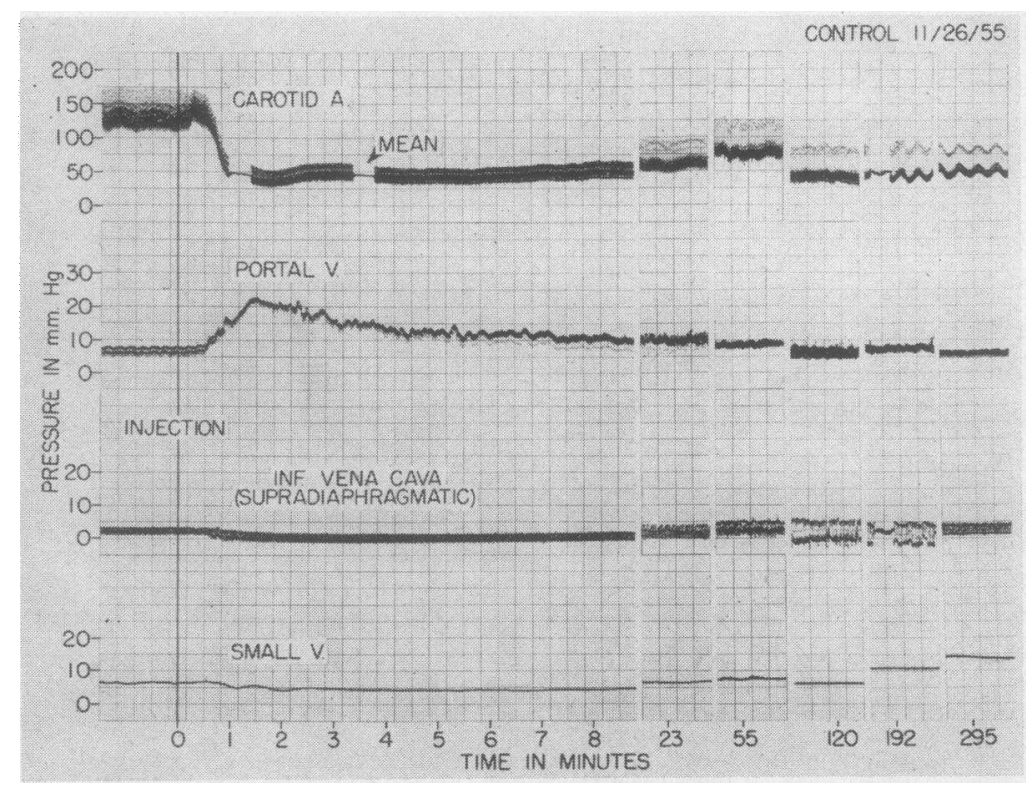

Fig. 2. Arterial and Venous Pressures Following the Injection of ENDOTOXIN 
a function of flow and resistance to filling in the right atrium. Constancy of this pressure indicated constant inflow and the absence of heart failure. The system was primed with $400 \mathrm{ml}$. of heparinized blood from a donor dog. The experimental animal was respired with air. Thoracotomy was performed by splitting the sternum. The azygos vein was ligated and $1 \mathrm{mg}$. per $\mathrm{kg}$. of heparin was injected intravenously. The atrial catheter was inserted through the auricular appendage and the superior vena cava was cannulated. Infusion at a rate equal to the superior vena cava flow was begun. A catheter was subsequently introduced into the inferior vena cava so that the entire venous return passed through the reservoir. The infusion pump was gradually speeded up until an average flow of approximately $85 \mathrm{ml}$. per $\mathrm{kg}$. was attained. This flow was maintained constant for the remainder of the experiment. In most instances between 100 and $300 \mathrm{ml}$. of blood were taken up from the reservoir before input and return were equal.

Serial electrocardiographic records of nine dogs were studied before and after initiation of hypotension with endotoxin. Limb lead tracings were obtained by reversing the conventional leg leads and positioning the right arm lead in the posterior neck.

\section{RESULTS}

\section{Venous pressures}

During the period when both the systemic blood pressure fell rapidly and the portal vein pressure rose, following the injection of endotoxin, the inferior vena cava pressures remained essentially unchanged (4 dogs), or decreased as much as 2 $\mathrm{mm}$. $\mathrm{Hg}$ (2 dogs). Subcutaneous small vein pressure fell 1.5 to $7 \mathrm{~mm}$. (3 dogs) during the same period. With partial recovery of the blood pressure and fall in portal vein pressure, the pressures of both the inferior vena cava and small veins returned to their previous levels (Figure 2). A small but progressive rise of small vein pressure occurred in two of the three animals after the second hour.

\section{Cardiac output and peripheral resistance. ${ }^{2}$}

After injection of the endotoxin there was a sharp decrease in cardiac output. With partial recovery of the arterial pressure, cardiac output was correspondingly increased (Table I). It was of considerable interest that changes in arterial

2 The kind cooperation of Dr. E. B. Brown and the technical assistance of Mrs. Lois Trank and Mr. Richard Clancy with this group of experiments are gratefully acknowledged.

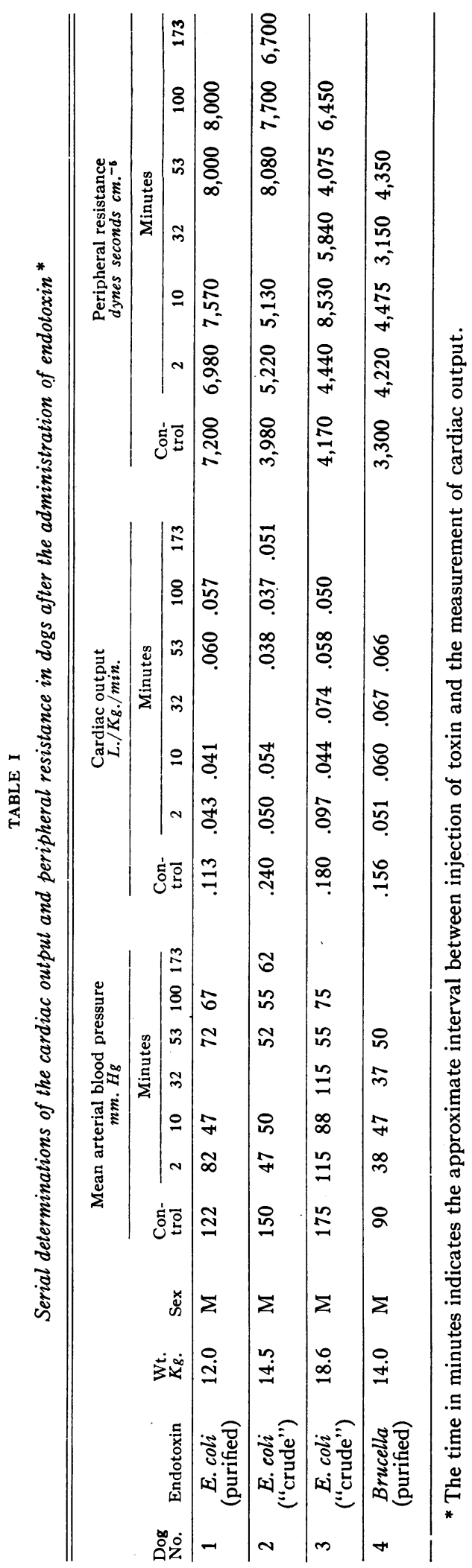




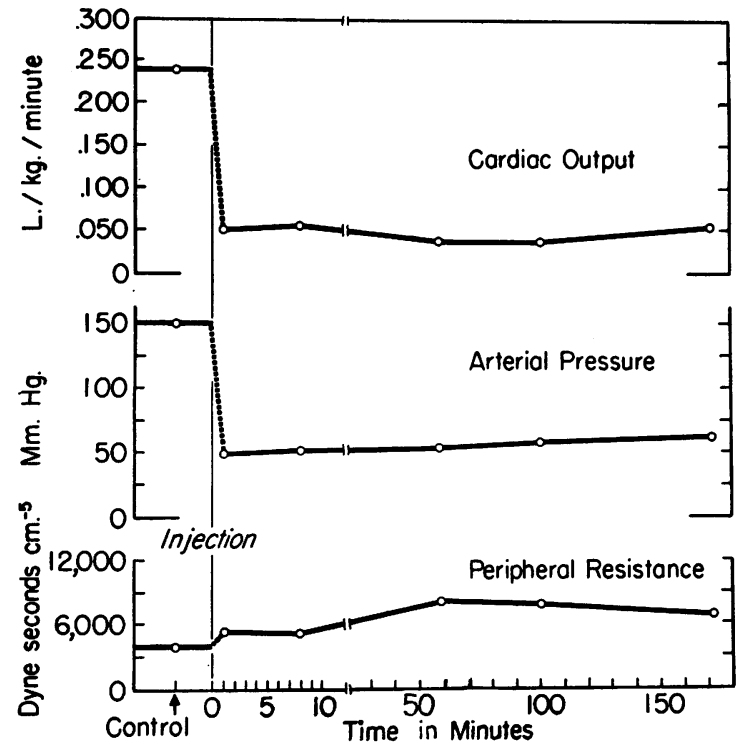

Fig. 3. Relationship of the Cardiac Output and the Calculated Peripheral Resistance to Arterial Pressure Following Injection of Endotoxin

pressure during the two hours following injection were closely correlated with changes of cardiac output (Figure 3 ). The calculated peripheral resistance remained essentially constant or rose. In no instance was it possible to attribute the arterial hypotension to a fall in calculated peripheral resistance.

\section{Total body perfusion}

When endotoxin was injected into the animals maintained by a mechanical "heart-lung" system, no fall in arterial blood pressure was observed. On the other hand, a rise of portal vein pressure was not prevented. During constant pressure perfusion (Figure 4), the accentuated rise in portal vein pressure proved that elevation of this pressure is a basic response to endotoxin which may occur without fall in arterial pressure.

\section{Venous return}

Injection of endotoxin into dogs maintained with constant cardiac filling was shortly followed by an exaggerated and prolonged elevation in portal vein pressure. Coincident with a rise in portal vein pressure there was a rapid decline in the level of blood contained in the reservoir due to a deficient venous return. Infusion pressure and arterial pressure remained constant. Large quantities of donor blood were added to the reservoir at short intervals to compensate for the inadequate venous return. Maximum pooling occurred in the first ten minutes and corresponded to the period of exaggerated portal pressure rise (Figure 5 and Table II). Continued slower loss occurred until termination of the experiment. Although some experiments were continued for periods up to three hours, data are reported only for the first half hour. The poor condition of the preparation, in part due to the loss of blood from rupture of distended blood vessels in the viscera, made observations in the later periods of the experiment of questionable significance.

\section{Electrocardiographic studies}

The heart rate was reduced on the average from 186 to 151 beats per minute after the initiation of hypotension with endotoxin. Over the next thirty minutes the heart rate gradually returned to its former level. No cardiac arrhythmia or conduc-

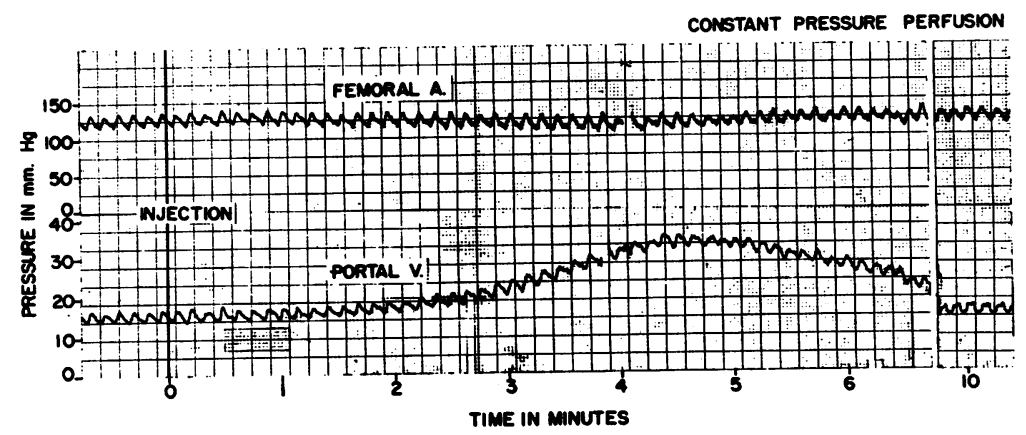

Fig. 4. Portal Vein Pressure Response to the Injection of Endotoxin during Total Body Perfusion at Constant Pressure 


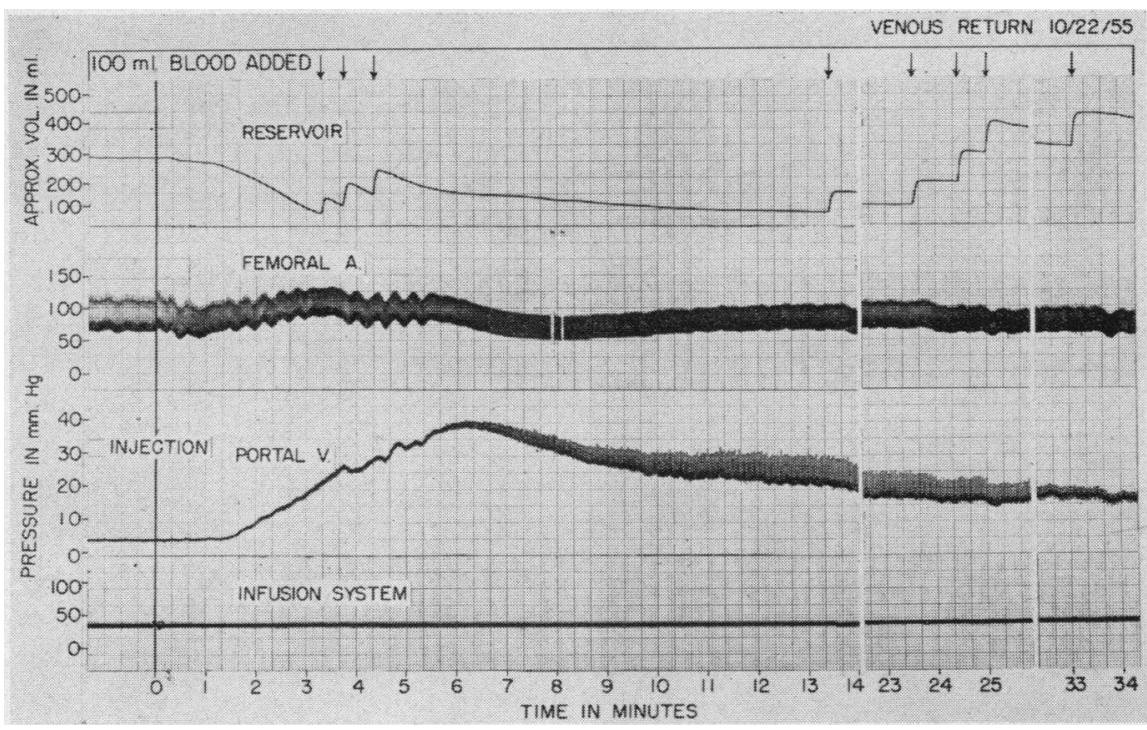

Fig. 5. Record Obtained in a Representative Experiment during Quantitation of Pooling Following the Injection of Endotoxin

tion defect was observed in any of nine animals studied. Segments of a typical record are shown in Figure 6.

\section{DISCUSSION}

Arterial hypotension occurring in the course of an overwhelming infection or initiated by the in- jection of bacterial products has variously been attributed to cardiac injury $(18,19)$, diffuse injury to capillaries and blood vessel walls resulting in loss of vasomotor tonus or leakage $(20-23)$, to an insult of the central nervous system $(24,25)$ or to a combination of two or more of such effects

TABLE II

Volume of blood pooled after injection of endotoxin

\begin{tabular}{|c|c|c|c|c|c|c|c|c|c|c|c|c|c|c|}
\hline \multirow[b]{2}{*}{ No. } & \multirow[b]{2}{*}{ Wt. } & \multirow[b]{2}{*}{ Sex } & \multirow[b]{2}{*}{ Endotoxin } & \multicolumn{4}{|c|}{$\begin{array}{c}\text { Arterial blood pressure } \\
\mathrm{mm} . \mathrm{Hg}\end{array}$} & \multicolumn{4}{|c|}{$\begin{array}{c}\text { Portal vein pressure } \\
\mathrm{mm} . \mathrm{Hg}\end{array}$} & \multicolumn{3}{|c|}{$\begin{array}{c}\text { Volume of blood pooled } \\
\mathrm{ml} . / \mathrm{kg} .\end{array}$} \\
\hline & & & & $0^{\prime \prime}$ & $5^{\prime \prime}$ & $10^{\prime \prime}$ & $30^{\prime \prime}$ & $0^{\prime \prime}$ & $5^{\prime \prime}$ & $10^{\prime \prime}$ & $30^{\prime \prime}$ & $5^{\prime \prime}$ & $10^{\prime \prime}$ & $30^{\prime \prime}$ \\
\hline \multirow[t]{2}{*}{1} & 19.0 & $F$ & E. coli & 112 & 108 & 110 & 130 & 7 & 35 & 17 & 8 & 36 & 46 & 68 \\
\hline & & & & 60 & 78 & 58 & 58 & & & & & & & \\
\hline \multirow[t]{2}{*}{2} & 9.0 & $\mathrm{~F}$ & E. coli & 165 & 195 & 125 & 135 & 6 & 50 & 48 & 13 & 51 & 82 & 103 \\
\hline & & & & 95 & 85 & 70 & 70 & & & & & & & \\
\hline \multirow[t]{2}{*}{3} & 9.5 & F & E. coli & 142 & 137 & 135 & 142 & 9 & 31 & 28 & 18 & 22 & 28 & 43 \\
\hline & & & & 102 & 82 & 85 & 75 & & & & & & & \\
\hline \multirow[t]{2}{*}{4} & 12.2 & $\mathbf{F}$ & E. coli & 120 & 115 & 97 & 110 & 4 & 31 & 24 & 15 & 30 & 41 & 51 \\
\hline & & & & 75 & 80 & 60 & 68 & & & & & & & \\
\hline \multirow[t]{2}{*}{5} & 8.0 & $\mathbf{M}$ & (crude, & 100 & 100 & 115 & 130 & 9 & 43 & 22 & 7 & 44 & 66 & 100 \\
\hline & & & & 40 & 40 & 45 & 30 & & & & & & & \\
\hline \multirow[t]{4}{*}{6} & 7.0 & F & E. coli & 165 & 170 & 190 & 85 & 5 & 38 & 15 & 9 & 61 & 61 & 114 \\
\hline & & & & 100 & 90 & 100 & 57 & & & & & & & \\
\hline & & Mean & & 134 & 138 & 129 & 122 & 7 & 38 & 26 & 12 & 40.7 & 54 & 79.8 \\
\hline & & & & 79 & 76 & 70 & 60 & & & & & & & \\
\hline
\end{tabular}




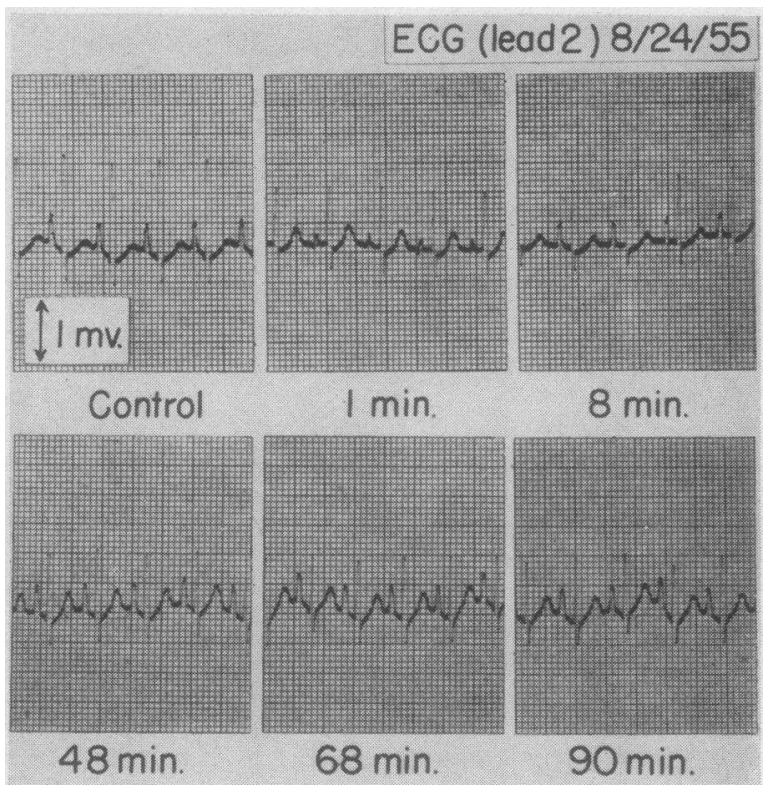

Fig. 6. Segments of a Typical Electrocardiographic Record Obtained at Intervals Following InJECTION OF ENDOTOXIN AT 0 Minutes

(26-28). In an earlier study we found that shock caused by endotoxin is not accounted for by a direct action of toxin on higher nervous centers (10). The possibility that endotoxin causes hypotension by action on the heart or on blood vessels generally was investigated in the present series of experiments.

It seems evident that the acute decline in arterial blood pressure, which occurred soon after the injection of endotoxin, was associated with a corresponding decline in cardiac output. There was no significant change or an increase in the calculated peripheral resistance and this suggested that arterial or arteriolar vasodilatation did not occur. The hypotensive state was fully accounted for by a fall in cardiac output to between 21 and 36 per cent of the control value. When cardiac output was artificially maintained at a constant value by a mechanical heart, no significant blood pressure decline was produced by endotoxin, offering further proof that shock was not due to a fall in peripheral resistance.

The inferior vena cava pressure was unaffected or decreased when shock was precipitated, consequently the fall in cardiac output could not be attributed to congestive heart failure. Direct observation of the heart in the open chested dog and electrocardiographic observations supplied no evi- dence that myocardial dysfunction was a factor in the production of shock.

A definitive demonstration of the hemodynamic changes involved was supplied by the venous return experiments. It was found that the injection of endotoxin produced a marked decrease in venous return. When the blood supply to the right atrium was artificially maintained through an exogenous source, the blood pressure did not fall. The heart was fully capable of normal function and both cardiac output and arterial blood pressure were unaltered as long as the large deficit in venous return was compensated for by augmented blood supply to the right heart.

The immediate hypotensive action of endotoxin in the $\operatorname{dog}$ is therefore attributable to an effect upon one or more areas of the body vasculature which results in the pooling of large quantities of blood or the extravasation of fluid. Since peripheral resistance does not fall, pooling must occur predominantly in the post-arteriolar vascular bed. We have already pointed to the portal venous system as a primary site of pooling. The amounts of fluid stored in the liver and intestine, quantitated by a gravimetric method previously described (12), account for most or all of the blood loss which is reflected as deficient venous return in the present experiments. It is to be noted, however, that in the intact animal a fall in the arterial pressure probably limits the extent of rise of liver and intestinal weight. When the blood pressure is maintained at normotensive levels by means of total body perfusion or compensation of deficient venous return, elevation of the portal vein pressure appears to be accentuated and the deficit in venous return is greater.

The initial pooling in the portal system is evidently caused by transient obstruction to venous outflow from the liver. We have measured pressures in unobstructed hepatic veins of dogs following injection of endotoxin and found that these vessels reflect the pressure conditions of the inferior vena cava rather than those of the portal vein. Essex and Thomas $(29,30)$ have demonstrated occlusive spasm of the intrahepatic vasculature of the dog and cat following administration of Ascaris suum extract, hydatid cyst fluid, and histamine, not attributable to a local sphincter mechanism or sluice valve at the junction of the hepatic veins and the inferior vena cava. Endo- 
toxins from gram-negative bacteria probably exert a similar action. This is supported by the observation that portal-caval anastomosis (Eck fistula) greatly modifies the immediate hypotensive reaction that follows injection of endotoxin, parasitic extracts, or anaphylaxis $(9,31,32)$. However, the hepatovascular phenomena which occur in various types of shock are as yet poorly understood.

There is no evidence at present that pooling occurs in systemic veins in the early period after endotoxin injection. In contrast to the marked elevation of portal vein pressure, a depression in the vena cavae and in small subcutaneous vein pressures was observed after injection of endotoxin.

Evidence that intravenous injection of endotoxin causes a significant increase in capillary permeability is lacking (33) and it is doubtful that leakage of fluid from the intravascular space can be implicated as the major factor in the production of the initial hypotensive state in the dog, although such leakage may be a factor in later stages. Studying shock produced by meningococcal toxin, Ebert, Borden, Hall, and Gold (23) also found a marked fall in cardiac output which was not attributable to changes in peripheral resistance. No regular change occurred in the hematocrit or plasma volume after such shock. However, prolongation of mixing time has been shown recently to be an important limiting factor in the estimation of blood volume during shock (34) and erroneously low volumes may be calculated.

The mechanism of the shock produced by a single injection of endotoxin is in several respects similar to anaphylactic shock and irreversible hemorrhagic shock. Almost a half century ago, Pearce and Eisenbrey experimentally demonstrated deficient venous return as the cause of anaphylactic hypotension by use of a donor dog in place of a reservoir system $(35,36)$. An increasing body of experimental evidence has led to a re-examination of physiological concepts as to the genesis of shock associated with infections. Although the most readily measured changes occur in the arterial bed, the cause of these changes in the early period after endotoxin has been, administered to dogs intravenously is found to be pooling of blood in specific post-capillary vessels.

\section{CONCLUSIONS AND SUMMARY}

Hypotension was produced in anesthetized dogs by intravenous injection of endotoxin derived from Escherichia coli and Brucella melitensis. The sharp fall in arterial pressure was accompanied by a marked rise in portal vein pressure and a fall in systemic venous pressure. Hypotension was produced by the fall in cardiac output without a decrease in the peripheral resistance. No evidence was found to indicate that myocardial failure was a factor in producing the hypotension. Total body perfusion prevented hypotension and intensified portal vein pressure elevation.

Venous return, measured by means of a reservoir system interposed between the great veins and the right heart, decreased markedly after injection of endotoxin. When cardiac filling was kept constant by an infusion system, the deficit in venous return was augmented and the portal vein pressure elevation was intensified, but the arterial pressure did not fall.

These observations indicate that the primary circulatory disturbance produced by endotoxin in dogs is mediated through an action on one or more specialized venous beds, including especially the vasculature of the liver. It is suggested that localized venous spasm in the hepatic venous system and possibly elsewhere produces pooling of large quantities of blood. The total venous return is thereby critically reduced and a fall in cardiac output and arterial blood pressure are inevitable end results, which account for the hypotension in this situation.

\section{REFERENCES}

1. Spink, W. W., Braude, A. I., Castaneda, M. R., and Goytia, R. S., Aureomycin therapy in human brucellosis due to Brucella melitensis. J. A. M. A., 1948, 138, 1145.

2. Hall, W. H., and Gold, D., Shock associated with bacteremia. Arch. Int. Med., 1955, 96, 403.

3. Weil, M. H., Clinical studies on a vasopressor agent: Metaraminol (Aramine). II. Observations on its use in the management of shock. Am. J. M. Sc. 1955, 230, 357.

4. Shear, M. J., Chemical treatment of tumors. IX. Reactions of mice with primary subcutaneous tumors to injection of a hemorrhage-producing bacterial polysaccharide. J. Nat. Cancer Inst., 1944, 4, 461.

5. Algire, G. H., Legallais, F. Y., and Park, H. D., Vascular reactions of normal and malignant tissues 
in vivo. II. The vascular reaction of normal and neoplastic tissues of mice to a bacterial polysaccharide from Serratia marcescens (Bacillus prodigiosus) culture filtrates. J. Nat. Cancer Inst., 1947, 8, 53.

6. Thomas, L., and Good, R. A., Studies on the generalized Schwartzman reaction. I. General observations concerning the phenomenon. J. Exper. Med., 1952, 96, 605.

7. Thomas, L., The physiological disturbances produced by endotoxins. Ann. Rev. Physiol., 1954, 16, 467.

8. Burrows, W., Endotoxins. Ann. Rev. Microbiol., 1951, 5, 181.

9. MacLean, L. D., and Weil, M. H., Hypotension (shock) associated with the administration of endotoxin (Gram-negative) to the dog. Circulation Research, In press.

10. Weil, M. H., MacLean, L. D., Visscher, M. B., and Spink, W. W., Investigations on the role of the central nervous system in shock produced by endotoxin from gram-negative microorganisms. J. Lab. \& Clin. Med., 1955, 46, 962.

11. Van Heyningen, W. E., Bacterial Toxins. Oxford, England, Blackwell Scientific Publications, 1950.

12. MacLean, L. D., Weil, M. H., Stish, R. J., Spink, W. W., and Visscher, M. B., Continuously recording quantitative estimation of circulatory changes in the liver and small intestine of the dog following Escherichia coli endotoxin administration. Federation Proc., 1956, 15, 123.

13. Spink, W. W., and Anderson, D., Experimental studies on the significance of endotoxin in the pathogenesis of brucellosis. J. Clin. Invest., 1954, 33, 540 .

14. Braude, A. I., Carey, F. J., Sutherland, D., and Zalesky, M., Studies with radioactive endotoxin. I. The use of $\mathrm{Cr}^{51}$ to label endotoxin of Escherichia coli. J. Clin. Invest., 1955, 34, 850.

15. Haddy, F. J., Richards, A. G., Alden, J. L., and Visscher, M. B., Small vein and artery pressures in normal and edematous extremities of dogs under local and general anesthesia. Am. J. Physiol., 1954, 176, 355.

16. Nicholson, J. W., III, and Wood, E. H., Estimation of cardiac output and Evans blue space in man, using an oximeter. J. Lab. \& Clin. Med., 1951, 38, 588.

17. Clark, L. C., Jr., Gollan, F., and Gupta, V. B., The oxygenation of blood by gas dispersion. Science, 1950, 111, 85.

18. Leese, C. E., and Greene, K. V., Physiological effects of bacterial polysaccharides upon the cardio-vascular and neuro-muscular systems. Federation Proc., 1949, 8, 93.

19. Leese, C. E., Poel, W. E., and Berman, H., Effects of the Shear bacterial polysaccharides upon cardiovascular response. Federation Proc., 1950, 9, 76.

20. Bradley, S. E., Chasis, H., Goldring, W., and Smith, H. W., Hemodynamic alterations in normotensive and hypertensive subjects during the pyrogenic reaction. J. Clin. Invest., 1945, 24, 749.

21. Ebert, R. V., Hagen, P. S., and Borden, C. W., The mechanism of shock in peritonitis. A study of the hemodynamics of shock occurring in peritonitis experimentally produced in dogs. Surgery, 1949, 25, 399.

22. Gilbert, R. P., Honig, K. P., Adelson, B. H., Griffin, J. A., and Becker, R., The hemodynamics of shock due to infection. J. Lab. \& Clin. Med., 1954, 44, 801.

23. Ebert, R. V., Borden, C. W., Hall, W. H., and Gold, D., A study of hypotension (shock) produced by meningococcus toxin. Circulation Research, 1955, 3, 378 .

24. Charrin, A., and Gley, E., Recherches expérimentales sur l'action des produits sécrétés par le bacille pyocyanique sur le système nerveux vaso-moteur. Arch. de Physiol. norm. et path., 1890, Ser. 5, 2, 724.

25. Penner, A., and Klein, S. H., The pathogenesis of experimental dysentery intoxication. Production of lesions by cerebral circulation of the toxin. J. Exper. Med., 1952, 96, 59.

26. Lockwood, J. S., The pathologic physiology of infection. Surg. Clin. N. America, 1946, 26, 1416.

27. Stead, E. A., Jr., Shock syndrome in internal medicine in Oxford Medicine. Christian, H. A., Ed., New York, Oxford University Press, 1945, Vol. II, Part II, p. 492 (133).

28. Ebert, R. V., and Stead, E. A., Jr., Circulatory failure in acute infections. J. Clin. Invest., 1941, 20, 671.

29. Essex, H. E., and Thomas, W. D., The response of the hepatic venous circulation to certain substances given intravenously. Proc. Staff Meet., Mayo Clin., 1950, 25, 34

30. Thomas, W. D., and Essex, H. E., Observations on the hepatic venous circulation with special reference to the sphincteric mechanism. Am. J. Physiol., 1949, 158, 303.

31. Graña, A., Mann, F. C., and Essex, H. E., Influence of the liver on the shock produced by extracts of certain parasites. Am. J. Physiol., 1947, 148, 243.

32. Manwaring, W. H., Serophysiologische Untersuchungen. 1. Der physiologische Mechanismus des anaphylaktischen Shocks. Ztschr. f. Immunitätsforsch. u. exper. Therap., 1910, 8, 1.

33. New light on endotoxins. Lancet, 1950, 1, 722.

34. Nylin, G., and Pannier, R., L'influence de l'orthostatisme et du shock sur la vitesse circulatoire déterminée a l'aide du phosphore radioactif. Arch. internat. de pharmacodyn. et de thérap., 1947, 73, 401.

35. Pearce, R. M., and Eisenbrey, A. B., A study of experimental conditions of low blood-pressure of non-traumatic origin. Arch. Int. Med., 1910, 6, 218.

36. Eisenbrey, A. B., and Pearce, R. M., A study of the action of the heart in anaphylactic shock in the dog. J. Pharmacol. \& Exper. Therap., 1912, 4, 21. 